\title{
Macronutrient intakes and food sources in Irish adults: findings of the North/South Ireland Food Consumption Survey
}

\author{
KE Harrington ${ }^{1,2, *}$ MJ McGowan ${ }^{1,2}$, M Kiely $^{3}$, PJ Robson ${ }^{4}$, MBE Livingstone ${ }^{4}$, \\ PA Morrissey and MJ Gibney ${ }^{3}$
}

Irish Universities Nutrition Alliance (IUNA) at: 'Department of Clinical Medicine, Trinity Centre for Health Sciences, St. James's Hospital, Dublin 8, Republic of Ireland: ${ }^{2}$ Present address: IUNA, 2nd Floor, Biotechnology Institute, Trinity College Dublin, Dublin 2, Republic of Ireland: ${ }^{3}$ Nutrition Sciences, Department of Food Science and Technology, University College, Cork, Republic of Ireland: ${ }^{4}$ Northern Ireland Centre for Diet and Health (NICHE), University of Ulster, Coleraine, Co. Londonderry, BT52 ISA, Northern Ireland

\begin{abstract}
Objective: To describe macronutrient intakes and food sources of the adult population in the Republic of Ireland and Northern Ireland and to assess adherence of this population to current dietary recommendations.

Design: A cross-sectional food consumption survey collected food intake data using a 7-day food diary.

Setting: Northern Ireland and the Republic of Ireland between October 1997 and October 1999.

Subjects: One thousand three hundred and seventy-nine adults aged 18-64 years (662 males and 717 females).

Results: Mean daily energy intakes in men were $11 \mathrm{MJ}$ per day, $15.5 \%$ was derived from protein, $34.8 \%$ from fat, $43.5 \%$ from carbohydrate and $5.9 \%$ from alcohol. Corresponding figures for women were $7.6 \mathrm{MJ}$ per day, $15.6 \%, 35.6 \%, 45.1 \%$ and $3.5 \%$. When alcohol energy was excluded the contribution of fat and carbohydrate to energy did not differ between men and women. When compared with existing dietary recommendations, $93 \%$ of men and $86 \%$ of women had protein intakes above the Population Reference Intake. Two approaches were used to assess adherence to the fat and carbohydrate dietary recommendations: (1) the proportion of individuals in the population attaining these dietary targets and (2) the proportion of the population that was included in a 'compliers' group which had a group mean equal to these dietary targets. Thirty-three per cent of men and $34 \%$ of women met the target of $35 \%$ of food energy from fat and $78 \%$ of men and $80 \%$ of women comprised the 'compliers' group having a group mean of $35 \%$ of food energy from fat. Twentythree per cent of men and $27 \%$ of women met the target of $50 \%$ of food energy from carbohydrate and $56 \%$ of men and $62 \%$ of women made up the 'compliers' group. Meat and meat products were the main source of fat $(23 \%)$ and protein $(37 \%)$, and bread and rolls (25\%) were the main source of carbohydrate.

Conclusion: A reduction in dietary fat intake remains an important public health issue in the Republic of Ireland and Northern Ireland. An increase in carbohydrate intake and attention to the rise in alcohol intake is also warranted.
\end{abstract}

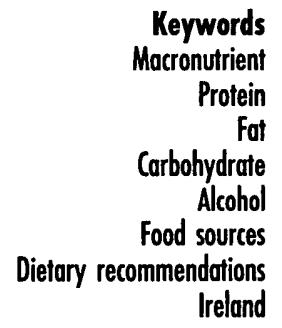

Keywords

Protent

Fot

ydrate

sources

Ireland
The significance of diet to health and disease has been much debated in devising dietary recommendations ${ }^{1-3}$. Nutrition and diet are considered important to the underlying risk factors for cardiovascular disease and cancer, the primary causes of premature mortality in most developed countries ${ }^{1,2,4-12}$. Cardiovascular disease and cancer accounted for $41 \%$ and $24 \%$, respectively, of all deaths in the Republic of Ireland in $1999^{13}$ and $43 \%$ and $25 \%$, respectively, of all deaths in Northern Ireland in $1997^{14}$. A reduction in dietary fat intake is currently the main focus of dietary recommendations in Europe. In addition, an increase in carbohydrate intake, an adequate protein intake and a reduction in the number of people exceeding guidelines for alcohol intake are also advocated.

Dietary recommendations for the UK population include Dietary Reference Values (DRVs) ${ }^{5}$ for nutrients, Health of the Nation dietary targets ${ }^{15,16}$ and qualitative healthy eating guidelines ${ }^{17}$. In the Republic of Ireland 
quantitative dietary guidelines ${ }^{18}$ exist and in 1995 the Nutrition Advisory Group (NAG) of the Department of Health set qualitative guidelines for the general population and subgroups of the population ${ }^{19}$. Quantitative targets for population intakes of macronutrients were to be set, but a lack of up-to-date information on food and nutrient intakes of the population at that time was a deterring factor. In 1999, Recommended Dietary Allowances for Ireland were revised ${ }^{20}$.

The North/South Ireland Food Consumption Survey (NSIFCS) was conducted between 1997 and 1999 to establish an up-to-date database of habitual food and drink consumption of Irish adults. This is the first large survey of its kind to be concurrently conducted on the populations of Northern Ireland and the Republic of Ireland using the same methodology. The aim of this paper is to describe current estimates of macronutrient intakes of adult men and women and to identify the primary food sources of macronutrients in the Irish diet. A further aim is to assess adherence of the population to current dietary recommendations for health promotion and disease prevention ${ }^{3,5,18}$.

\section{Methods}

The North/South Ireland Food Consumption Survey was a cross-sectional study of the food and nutrient intakes of a representative sample of adults aged 18-64 years in the Republic of Ireland and Northern Ireland. Fieldwork was carried out between October 1997 and October 1999. A detailed description of the sampling procedure is presented elsewhere in this supplement ${ }^{21}$. Eligible subjects who were between the ages of 18 and 64 years and who were neither pregnant nor breast-feeding were invited to participate. In all, 1379 subjects completed the full dietary survey, with a response rate of $63 \%{ }^{21}$. In addition to food intake data, information on health and lifestyle practices and socio-demographic, attitudinal, restrained eating, physical activity and anthropometry were collected.

\section{Dietary assessment}

A food diary was used to collect food and nutrient intakes over a period of 7 days. Harrington $e$ al $^{22}$ have described the methods used in detail. Subjects recorded each item of food and drink consumed, the amount, brand name (where possible) and method of cooking. Details of recipes used, including ingredients, were requested and food or drinks eaten out were recorded. The subjects were visited four times by the fieldworker according to the food diary instruction model. Food and drink consumed were quantified by eight specific methods according to a quantification protocol ${ }^{22}$ including a photographic food atlas ${ }^{23}$, direct weighing of specific items of food and drink consumed, manufacturer's data, 'fast food' portion sizes, household measures and standard portion sizes ${ }^{22,24}$.

\section{Nutrient analysis}

Food and nutrient analysis was conducted using WISP (Weighed Intake Software Package), a nutrient analysis program customised for data entry for this survey (Tinuviel Software, Warrington, UK). WISP uses McCance and Widdowson's food tables ${ }^{25}$ and published supplements ${ }^{26-34}$ to generate nutrient data. One thousand and ten new food codes were added to the existing databank to include food composition data of manufactured foods or fluids not present, to enable the analysis of recipes and to include nutritional supplements ${ }^{22}$. The mean daily nutrient intake was analysed for each individual. Food codes used were also categorised into 18 major food groups and the contribution of these 18 food groups to mean daily protein, fat and carbohydrate intake was calculated.

\section{Comparison with dietary recommendations}

The mean daily intakes of macronutrients of men and women of the NSIFCS were compared with existing dietary guidelines and recommended intakes ${ }^{3,5,18}$. Two different calculations were used in evaluating the attainment of dietary recommendations. Approach 1 calculated the percentage of individuals in the population who met the dietary target for a macronutrient, for men and women and in each of three age categories. Dietary targets and recommendations, however, are set as average intakes for the population and not as individual targets. Approach 2 takes this into account by calculating the maximum size of a subgroup of the population known as 'compliers', whose mean intake equals the population dietary recommendation. Both approaches were used for fat and carbohydrate (Table 2). Approach 2 has been described by both Wearne and Day ${ }^{35}$ and the Ministry of Agriculture, Fisheries and Food (MAFF) $)^{36}$. For fat ( $\%$ of total energy and food energy from fat), the mean intakes for each individual were ranked in ascending order from lowest to highest. The mean intake of the compliers group (to equal the fat targets of $33 \%$ of total energy from fat or $35 \%$ of food energy from fat) was then calculated by starting with the individual with the lowest mean fat intake and including subsequent individuals in the calculation of a group mean intake until the addition of one more individual caused the group mean to exceed the fat target ${ }^{5,18}$. For carbohydrate (\% of total energy and food energy from carbohydrate) the same approach was used, except that mean intakes for each individual were ranked in descending order from highest to lowest. Successive individuals were then added until the addition of the next individual caused the group mean to fall below a target of $47 \%$ of total energy and $50 \%$ of food energy from carbohydrate ${ }^{5}$. For comparative purposes, the Irish National Nutrition Survey (INNS) database was 
used to calculate the proportion of individuals attaining recommendations, using approaches 1 and 2, in 1988/89 in adults aged 18-64 years taking part in the INNS ${ }^{37}$.

\section{Statistical analysis}

Statistical analysis was performed using SPSS ${ }^{\circledR}$ (version 9.0.1, SPSS Inc., Chicago, IL). Mean \pm standard deviation (SD) was calculated for daily intakes of macronutrients by gender and age. The contribution of 18 food groups to protein, fat and carbohydrate intake was calculated by gender and age. Differences in mean intakes between men and women were assessed using independent $t$-tests. Differences between age groups within each sex were evaluated using one-way analysis of variance (ANOVA) for multiple comparisons. When statistically significant effects were encountered $(P<0.05)$, comparisons of means were made using Scheffe post-hoc multiple comparisons to ascertain which specific means differed. For variables that did not follow a normal distribution, as in the case of alcohol and some food groups, the MannWhitney and Kruskal-Wallis non-parametric tests were used for comparison of two or more groups, respectively. Post-hoc comparisons of mean daily intakes of alcohol or $\%$ energy from alcohol across age groups in women was not possible, as the data did not satisfy the assumptions of homogeneity of variance ${ }^{38}$. Values of $P<0.05$ were taken as statistically significant. Tables were created using Microsoft ${ }^{\circledR}$ Excel spreadsheets (version 1997 SR-2, Microsoft Corporation, Redmond, WA).

\section{Results}

Table 1 presents mean daily energy and macronutrient intakes of all men and women and according to age group. Men had higher energy intakes than women and consequently higher intakes of all macronutrients $(P<$ 0.001 ). When energy from alcohol was excluded, the contribution of fat and carbohydrate to energy did not differ between men and women. A small but statistically significant difference between men and women in the proportion of food energy from protein was observed $(P=0.021)$. When alcohol energy was included, however, women had greater proportions of energy from fat (35.6\%) than men $(34.8 \%)(P=0.005)$. It is noteworthy that women aged $18-35$ years $(P=0.022)$ and $51-64$ years $(P=0.042)$ reported greater proportions of total energy from fat than the men of those age groups, with no differences between the men and women aged 36-50 years. Similarly, when energy from alcohol was included, women (18-64 years) had greater proportions of total energy from carbohydrate than men $(P<0.001)$ but intakes of total energy from protein did not differ between men and women.

With increasing age, fat intakes (\% food energy) decreased with 51-64-year-old men and women having lower fat intakes than the other two age groups
$(P<0.001)$. Carbohydrate intakes (\% food energy) increased with age in men $(P<0.01)$ but not in women. Protein intakes (\% food energy) increased with age in both men and women $(P<0.001)$.

The distribution of alcohol intake (as $g /$ day) reported was skewed, with median intakes of $13 \mathrm{~g}$ and $4 \mathrm{~g}$ for men and women, respectively (data not shown). Mean daily alcohol intake $(\mathrm{g})$ for men was 2.5 times that for women $(P<0.001)$. A trend of decreasing alcohol intake with increasing age was observed in both men and women.

When compared with existing recommendations, protein intake in adults was found to be adequate. Mean daily protein intakes of men and women of all age groups were higher than the Population Reference Intake $(\mathrm{PRI})^{3,20}$ of $56 \mathrm{~g}$ for males and $47 \mathrm{~g}$ for females (Table 1). As many as $93 \%$ of men and $86 \%$ of women had protein intakes above the PRI (expressed as $0.75 \mathrm{~g}$ of protein $/ \mathrm{kg}$ body weight/day $)^{3,20}$ with mean daily protein intakes of 1.2 and $1.1 \mathrm{~g} / \mathrm{kg}$ body weight $/$ day for men and women, respectively (data not shown). Some $2 \%$ of men and $4 \%$ of women consumed mean daily protein intakes less than or equal to the Average Requirement (AR, expressed as $0.6 \mathrm{~g}$ of protein $/ \mathrm{kg}$ body weight/day) ${ }^{3,20}$. Only $1 \%$ of both men and women had protein intakes less than or equal to the Lower Threshold Intake (LTI, expressed as $0.45 \mathrm{~g} / \mathrm{kg}$ body weight/day) $)^{3,20}$.

Table 2 presents a comparison of the proportions of men and women in each age group who had total fat and carbohydrate intakes (\% energy) that were compatible with current dietary recommendations ${ }^{5,18}$ using approaches 1 and 2 as described in the Methods section.

The mean daily percentages of total energy and food energy from fat for men and women exceeded current recommendations ${ }^{5,18}$ of $33 \%$ and $35 \%$, respectively (Table 2). Men and women aged 51-64 years were the only subgroup of this population with mean intakes close to the food energy target for fat. When energy from alcohol was included, only men aged 51-64 years had mean intakes close to the total energy target for fat. The proportions of men and women in the population achieving fat recommendations for food energy using approach 1 were $33 \%$ of men and $34 \%$ of women, and for total energy were $35 \%$ of men and $30 \%$ of women. Using approach 2, the maximum size of the 'compliers' group with a group mean equal to the food energy target was $78 \%$ for men and $80 \%$ for women, and with a group mean equal to the total energy target was $82 \%$ for men and $71 \%$ for women.

Carbohydrate intakes were lower than the Dietary Reference Values (DRVs) ${ }^{5}$ for all age groups of men and women (Table 2). Using approach 1, 23\% of men and $27 \%$ of women met the food energy target for carbohydrate and $29 \%$ of men and $37 \%$ of women met the total energy target. Using approach 2 , the maximum size of the 'compliers' group with a group mean equal to the food energy target for carbohydrate was $56 \%$ for men and 


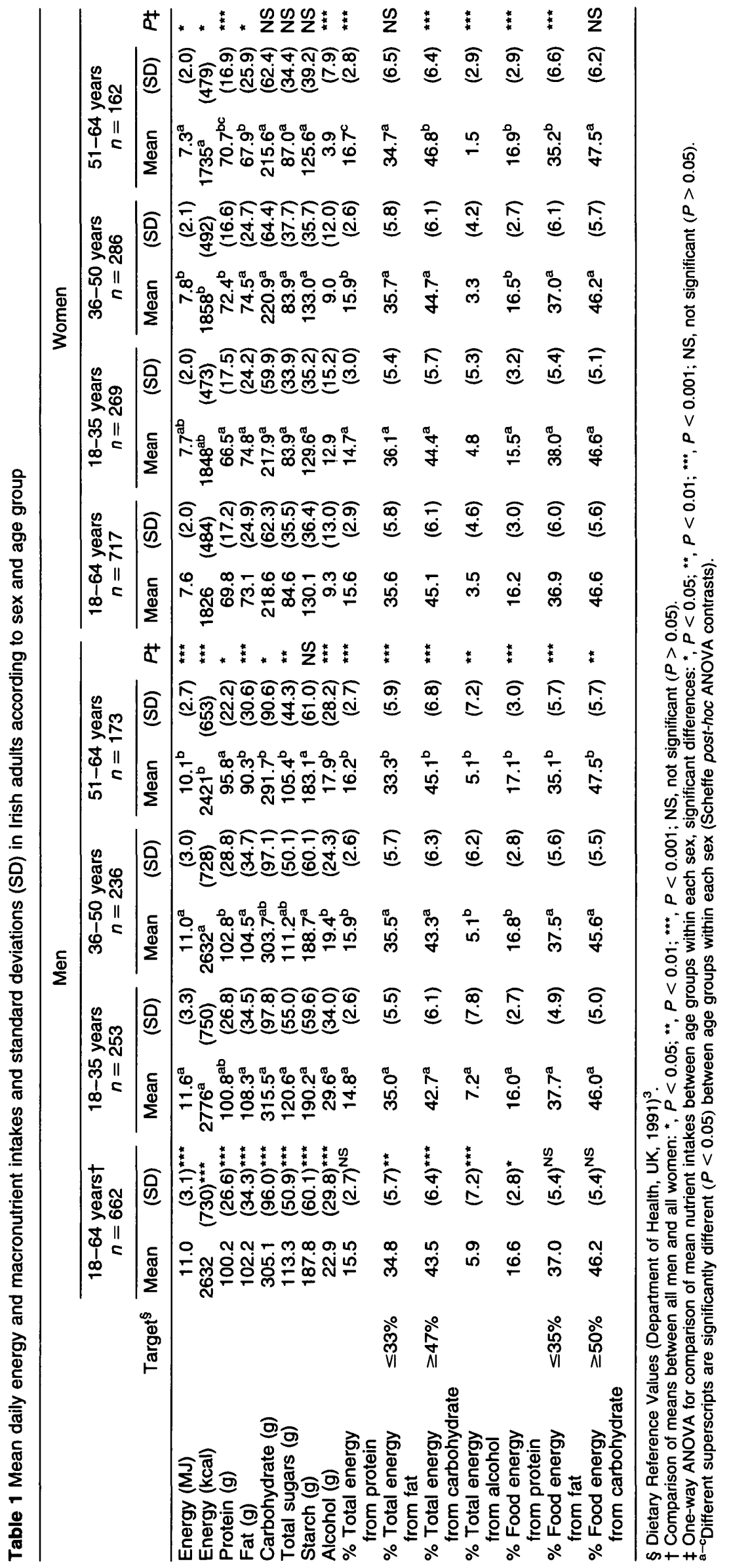



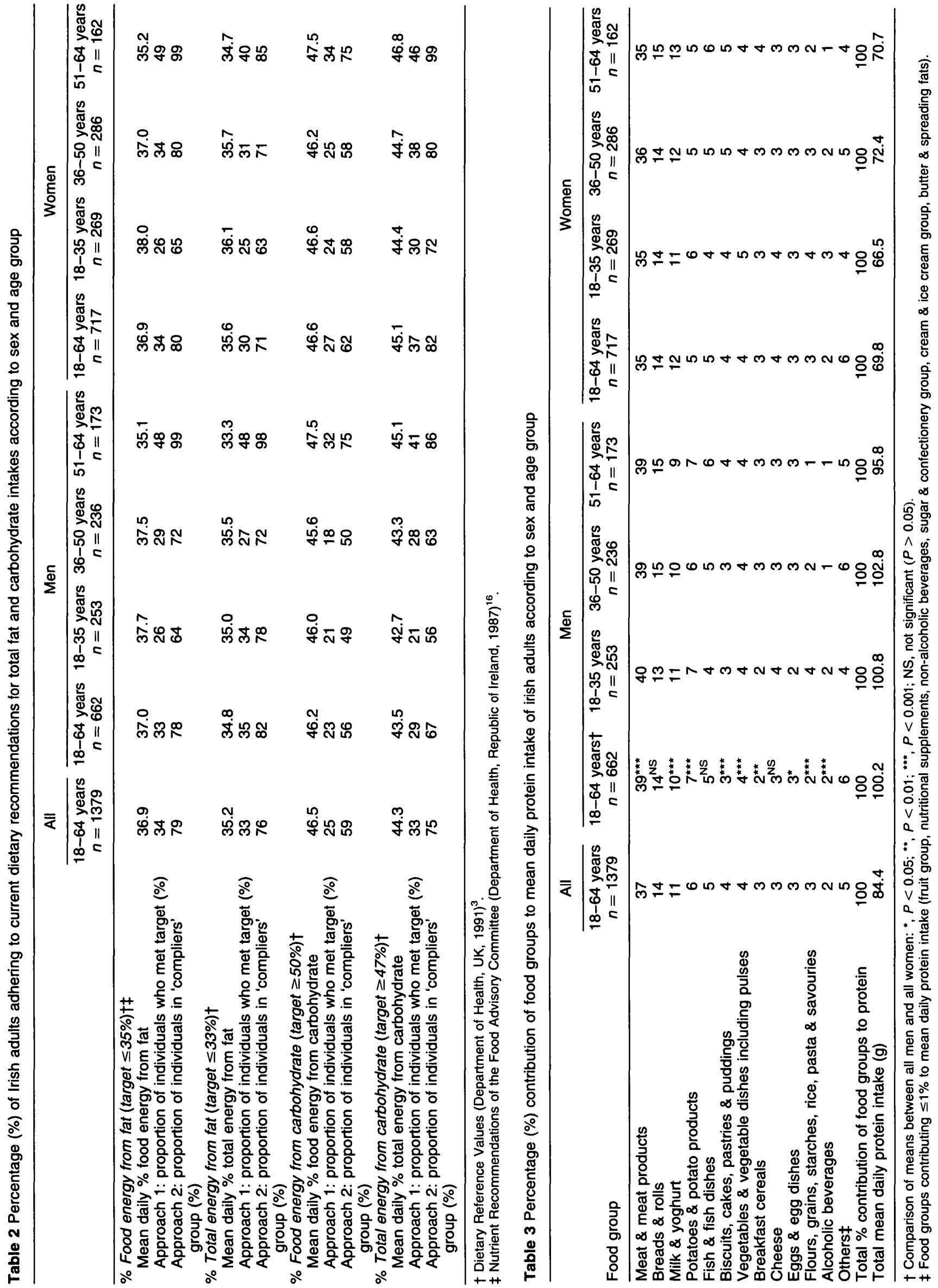
$62 \%$ for women, and with a group mean equal to the total energy target was $67 \%$ for men and $82 \%$ for women.

The proportion of individuals in the population and the proportion of individuals in the 'compliers' group who met these fat or carbohydrate recommendations (\% total energy or \% food energy) showed a tendency of increasing proportions of both men and women attaining targets with increasing age.

Tables 3-5 show the main food sources of protein, fat and carbohydrate intakes by gender and age, respectively. In each table, food groups are ranked according to their percentage contribution to mean daily macronutrient intakes for all adults (18-64 years). The food sources of each macronutrient were similar within the various age-sex groupings in terms of both the percentage contribution and the ranking of the food group, with a few exceptions.

Table 3 presents the food groups contributing to protein intake. 'Meat and meat products' were the main source of protein (37\%) followed by 'breads and rolls' (14\%) and 'milk and yoghurt' (11\%). Men obtained a greater proportion of their protein from 'meat and meat products' and 'potatoes and potato products' than did women $(P<0.001)$. Women derived more protein from 'milk and yoghurt' $(P<0.001)$. The contribution of 'breads and rolls' to protein intake increased with increasing age in men $(P<0.001)$. Both men $(P=0.001)$ and women $(P<0.001)$ derived more protein from 'fish and fish products' with increasing age. The contribution of 'milk and yoghurt' to protein intake increased with increasing age in women $(P=0.008)$ but it decreased with increasing age in men $(P=0.025)$.

Table 4 presents the food groups contributing to fat intake in the Irish diet. 'Meat and meat products' and 'butter, spreading fats and oils' provided $40 \%$ of total fat intake. 'Biscuits, cakes, pastries and puddings' and 'milk and yoghurt' each provided $9 \%$. 'Potatoes and potato products' contributed $7 \%$ to fat intake, most likely by the inclusion of chipped potatoes in this food group category. Men had greater intakes of fat from 'meat and meat products' $(P<0.001)$, 'butter, spreading fats and oils' $(P=0.001)$ and 'potatoes and potato products' $(P<$ $0.001)$ than women. Women derived more fat from 'biscuits, cakes, pastries and puddings' and 'vegetables and vegetable dishes' than men $(P<0.001)$. With increasing age, the contribution of the 'butter, spreading fats and oils' and 'biscuits, cakes, pastries and puddings' to fat intake increased in both males and females $(P<$ 0.001). Fat intakes from 'potatoes and potato products' and 'sugars, preserves, confectionery and savoury snacks' decreased with increasing age in both men and women $(P<0.001)$.

Table 5 lists the food groups contributing to carbohydrate intake. 'Breads and rolls' and 'potatoes and potato products' provided $42 \%$ of carbohydrate intake. 'Biscuits, cakes, pastries and puddings' and 'sugars, preserves, confectionery and savoury snacks' together provided $20 \%$ of carbohydrate intake. Breakfast cereals, the fruit and fruit juices group and 'milk and yoghurt' each contributed $6 \%$. Men derived more carbohydrate from 'potatoes and potato products' than women $(P<0.001)$ and women obtained more carbohydrate than men from 'biscuits, cakes, pastries and puddings' and the fruit group $(P<$ $0.001)$. As age increased, 'breads and rolls' contributed more to the carbohydrate intakes of men $(P<0.001)$. Women derived more carbohydrate from 'milk and yoghurt' $(P=0.001)$ with increasing age but men derived less $(P=0.015)$. The contribution of 'biscuits, cakes, pastries and puddings' $(P<0.001)$ and the fruit group $(P<0.05)$ to carbohydrate intakes increased with increasing age, with greater contributions to the intakes of women than men in all age groups.

\section{Discussion}

This survey is a comprehensive investigation of the food and nutrient intakes of a representative sample of adults in the Republic of Ireland and Northern Ireland. The mean ratio of energy intakes to estimated basal metabolic rate $\left(\mathrm{EI} / \mathrm{BMR}_{\mathrm{est}}\right)$ is used to assess the validity of reported energy intakes ${ }^{39-41}$ and was 1.38 in this population ${ }^{42}$. While lower than the expected mean EI/BMR $\mathrm{Bst}_{\text {est }} 1.53$ proposed by Goldberg et al. ${ }^{40}$ for a population of this size with 7 days of food intake data, this mean EI/BMR est $_{\text {value }}$ is comparable to that reported in other large food intake surveys $^{39,43,44}$.

To evaluate adherence to dietary guidelines, two approaches were used in this paper (Table 2). The results of evaluating adherence to fat intake (\% total energy) in the NSIFCS data were comparable to results obtained from re-analysis of the INNS data, using approaches 1 and 2 (unpublished data) ${ }^{37}$. Thirty-three per cent of all adults in the NSIFCS met the target for fat (\% total energy) compared with $35 \%$ of all adults in the INNS ${ }^{37}$ (approach 1 ). The proportion of individuals comprising the maximum size of the 'compliers' group, with a group mean equivalent to the fat target ( $33 \%$ total energy), was $82 \%$ for men and $71 \%$ for women of the NSIFCS and $78 \%$ for men and $77 \%$ for women of the INNS ${ }^{37}$ (approach 2). The proportion of the population adhering to dietary fat recommendations in Great Britain in 1986/1987 was lower: $14 \%$ of all adults met the target for total fat and $41 \%$ of men and $31 \%$ of women comprised the 'compliers' group $^{36}$.

Recommendations for dietary fat intakes, devised to reduce the risk of cardiovascular disease and cancer - the major causes of premature mortality, are the most frequently assessed dietary guidelines ${ }^{1,2,4}$. Recommendations advise dietary fat intake in the region of $33 \%$ of total energy or $35 \%$ of food energy ${ }^{5,18}$. Our findings show that, irrespective of the approaches used in evaluating the fat 

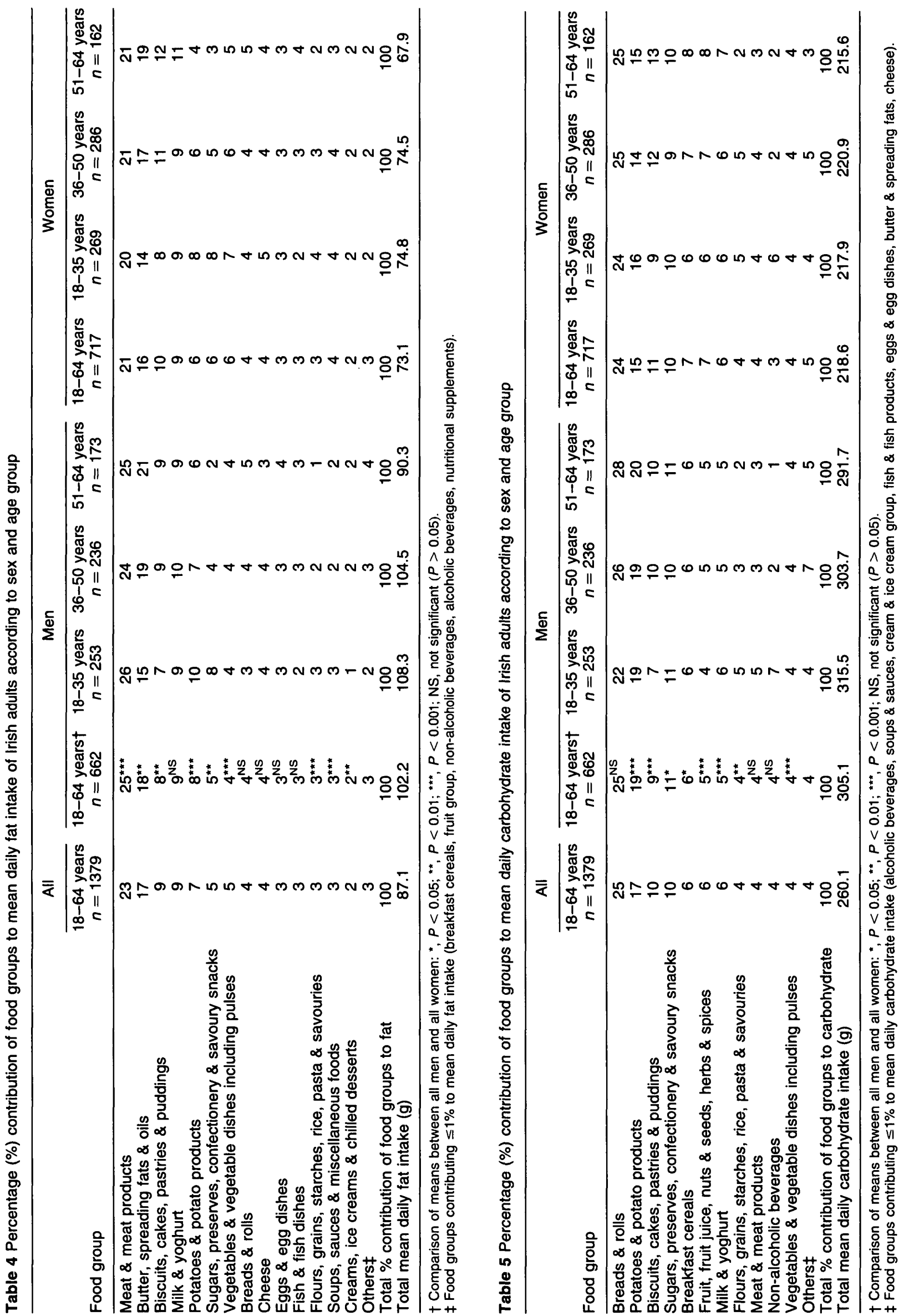
intakes of men and women of the NSIFCS, intakes are higher than recommended targets and a reduction in fat intake is still warranted.

The trend of decreasing fat intake with increasing age requires further investigation before the men and women aged 51-64 years can be excluded from future targeting of advice on dietary fat reduction. Although men and women in this age group had mean daily fat intakes close to current recommendations (\% food energy from fat) and had the greatest proportions meeting fat targets using both approaches 1 and 2, these data may be confounded by a number of factors. Mean EI/BMR est values in this age group were lower than those reported in younger age groups, suggesting that underreporting of energy intake may have occurred ${ }^{42}$. Furthermore, body mass index (BMI) and the prevalence of obesity were highest in this age group of adults ${ }^{45}$ and indeed it has been well documented that the overweight and obese are more likely to underreport energy intakes than those of normal weight ${ }^{46,47}$. The influence of underreporting on macronutrient intakes (\% energy) is somewhat unclear. Diets lower in fat (expressed as \% of total energy) have been reported in underreporters compared with acceptable reporters ${ }^{46-48}$. Some investigators, however, have reported that the contribution of macronutrients to energy (\% total energy) does not appear to be grossly different between underreporters and acceptable reporters ${ }^{49-51}$. This latter finding would suggest that the lower fat intakes reported by those aged 51-64 years are valid even with evidence of underreporting. Lower energy intakes in those consuming low-fat diets compared with those consuming high-fat diets have been reported ${ }^{52,53}$ and this was also observed in the present study, with lower mean daily energy intakes in this group of 51-64 year olds (Table 1). When interpreting the influence of underreporting on the proportions of energy from macronutrients, consideration must also be given, however, to the different cut-off criteria used to define underreporters. While more investigative research is needed to understand and interpret the relationship between underreporting, the prevalence of obesity and dietary fat intake, it remains the case that dietary fat intake in Ireland needs to be further reduced. All age groups of men and women need to be targeted considering the lower fat targets of $\mathrm{WHO}^{4}$ and the European Heart Network $^{1}$ who recommend a population average of $30 \%$ of energy intake as an upper limit for total fat intake, which is of course lower than the recommendations evaluated in this paper.

The marked increase in alcohol intake reported over the past decade is an important public health concern that also needs to be addressed. Alcohol recommendations are set for individuals, unlike recommendations for other macronutrients that are population-based ${ }^{54,55}$. Mean daily alcohol intake underestimates the quantity of alcohol consumed by alcohol-drinking adults, as non-drinkers are included in this mean value. Furthermore, alcohol intake ( $g /$ day) collected using the 7-day food diary refers to alcohol intake during this period only. It has been estimated that 20-50 days of assessment are required to get an estimate of usual alcohol intake for individuals ${ }^{2}$. Sixty-five per cent of this population reported to consume alcohol using the food diary data ( $70 \%$ of all men and $61 \%$ of all women). Questionnaire data from this population included estimates of usual alcohol intake and found that $80 \%$ of the population was consuming alcohol ( $81 \%$ of all men and $79 \%$ of all women), with $36 \%$ of these men and $20 \%$ of these women consuming greater than recommended limits of alcohol intake, of 21 units for men and 14 units for women (expressed as units of alcohol per week $)^{55}$. Alcohol must continue to be included in future strategies to improve health and prevent the problems associated with excessive alcohol consumption that are detrimental to health ${ }^{56-58}$.

All men and women should increase carbohydrate intakes as only $25 \%$ of all individuals met the carbohydrate recommendations (\% food energy) and only $59 \%$ of all adults were included to comprise the maximum size of the 'compliers' group with a group mean meeting this population target (Table 2). Protein intakes were adequate for nearly all individuals (93\% of men and $86 \%$ of women had protein intakes above the $\mathrm{PRI}^{3}$ ). Some $21 \%$ of men and $8 \%$ of women of the NSIFCS had intakes greater than or equal to $1.5 \mathrm{~g} / \mathrm{kg}$ body weight/day, twice the $\mathrm{PRI}^{3}$ (data not shown). Although twice the $\mathrm{PRI}^{3}$ has been used as a guideline threshold for high protein intakes, Millward ${ }^{59}$ has recently proposed re-evaluation of this value as it can easily be exceeded by individuals with a high energy expenditure ${ }^{59}$. Indeed, the scientific case for excessive protein intakes being a risk to renal function and bone health ${ }^{3,5}$ remains uncertain and has recently been reported to be weak ${ }^{59}$.

After evaluating the attainment of macronutrient guidelines in a population and identifying the nutrient(s) to be targeted, for example fat in the NSIFCS, the food sources of the target nutrient must be determined ${ }^{2}$. The foods to be included in food-based dietary guidelines can then be identified so as to enable modification of the target nutrient(s) intake. Tables 3-5 present the food sources of protein, fat and carbohydrate, respectively. It is not correct, however, to advocate changes in the consumption of a food group without investigating the contribution of individual foods within a food group to the nutrient of concern ${ }^{2}$. This facilitates more specific targeting, as the individual foods in a food group can contribute to the intake of a nutrient by different amounts. The contribution of the food group to the intake of other nutrients must also be evaluated ${ }^{2}$. These issues arise in examining the sources of dietary fat for this population with a view to targeting dietary fat reduction (Table 4).

Meat and meat products were the greatest source of fat in the NSIFCS. This food group, however, was also the 
greatest source of protein for men and women (Table 3) and the second largest source of iron for men (20\%) and women $(16 \%)^{60}$. A reduction in the consumption of this food group cannot be advised without investigation of the contribution of individual foods within this group to total dietary fat intake. The practice of trimming visible fat from meat and the cooking methods used must also be determined.

The 'milk and yoghurt' group was also important as a source of total dietary fat and is targeted in healthy eating guidelines in order to reduce dietary fat intakes, with advice to choose lower-fat varieties ${ }^{17,18}$. This food group is an important source of calcium however. Mean daily calcium intakes of men and women of the NSIFCS ${ }^{60}$ (949 $\mathrm{mg}$ and $742 \mathrm{mg}$, respectively) were also lower than those observed in men and women aged 18-64 years in the INNS (1227 $\mathrm{mg}$ and $869 \mathrm{mg}$, respectively; unpublished data) ${ }^{37}$. Although the food groupings used in each study were not identical, these findings must be considered in the formulation of food-based dietary guidelines with respect to reducing fat intakes. Further analysis is required to determine whether advice to reduce dietary fat intake has resulted in decreased consumption of all milks (full-fat and lower-fat varieties) to the point that calcium intakes are compromised. This is of great concern given reports of the increasing incidence of osteoporosis in Europe ${ }^{61,62}$. Lower than recommended calcium intakes may impair achievement of maximal adult peak bone mass.

In conclusion, a reduction in dietary fat intake remains an important public health issue in the Republic of Ireland and Northern Ireland. Attempts to increase dietary carbohydrate intake should also continue to be included in future recommendations so as to replace the energy deficit from reduced fat intakes. Attention must also be given to the rise in alcohol intake. A challenge still exists for all involved in the promotion of public health to devise focused strategies to increase the proportion of the population in the Republic of Ireland and Northern Ireland who adhere to current macronutrient recommendations.

\section{References}

1 European Heart Network. Food, Nutrition and Cardiovascular Prevention in the European Union. Luxembourg: European Heart Network, 1998.

2 FAO/WHO. Preparation and Use of Food-based Dietary Guidelines. WHO Technical Report Series 880. Geneva: World Health Organization (WHO), 1998.

3 Scientific Committee for Food. Nutrient and Energy Intakes for the European Community. Reports of the Scientific Committee for Food, 31st Series. Luxembourg: Office for Official Publications of the European Communities, 1993.

4 World Health Organization (WHO). Diet, Nutrition and the Prevention of Cbronic Diseases. WHO Technical Report Series No. 797. Geneva: WHO, 1990.

5 Department of Health. Dietary Reference Values for Food
Energy and Nutrients for the United Kingdom. Report of the Panel on Dietary Reference Values of the Committee on Medical Aspects of Food Policy. London: HMSO, 1991.

6 Department of Health. Nutritional Aspects of Cardiovascular Disease. Report of the Cardiovascular Review Group of the Committee on Medical Aspects of Food Policy. London: HMSO, 1994.

7 Food and Agriculture Organisation (FAO). Fats and Oils in Human Nutrition. Report of a joint expert consultation. Rome: FAO, 1994.

8 World Cancer Research Fund. Food, Nutrition and the Prevention of Cancer: A Global Perspective. Washington, DC: American Institute for Cancer Research, 1997.

9 Department of Health. Nutritional Aspects of the Development of Cancer. Report of the Working Group on Diet and Cancer of the Committee on Medical Aspects of Food and Nutrition Policy. London: HMSO, 1998.

10 Sugimura $T$. Nutrition and dietary carcinogens. Carcinogenesis 2000; 21: 387-95.

11 Reddy BS. The Fourth DeWitt S. Goodman lecture. Novel approaches to the prevention of colon cancer by nutritional manipulation and chemoprevention. Cancer Epidemiol. Biomark. Prev. 2000; 9: 239-47.

12 Giovannucci E. Nutritional factors in human cancers. $A d v$. Exp. Med. Biol. 1999; 472: 29-42.

13 Central Statistics Office (CSO). Vital Statistics 4 th Quarter and Yearly Summary 1999. Dublin: CSO, 2000.

14 British Heart Foundation. Coronary Heart Disease Statistics. British Heart Foundation Statistics 1999. London: British Heart Foundation, 1999.

15 Department of Health. The Health of the Nation: A Strategy for Health in England. Cm1986. London: HMSO, 1992.

16 Department of Health. Our Healtbier Nation: A Contract for Health. Cm3852. London: Stationery Office, 1998.

17 HEA/MAFF/Department of Health. Eight Guidelines for $A$ Healthy Diet. London: Health Education Authority (HEA), 1997.

18 Food Advisory Committee. Guidelines for Preparing Information and Advice to the General Public on Healthy Eating. Dublin, Ireland: Department of Health, 1987.

19 Nutrition Advisory Group. Recommendations for a Food and Nutrition Policy for Ireland. Dublin: Stationery Office, 1995.

20 Food Safety Authority of Ireland (FSAI) Nutrition Subcommittee. Recommended Dietary Allowances for Ireland. Dublin: FSAI, 1999; 16-7.

21 Kiely M, Flynn A, Harrington KE, Robson PJ, Cran G. Sampling description and procedures used to conduct the North/South Ireland Food Consumption Survey. Public Health Nutr. 2001; 4(5A): 1029-35.

22 Harrington KE, Robson PJ, Kiely M, Livingstone MBE, Lambe J, Gibney MJ. The North/South Ireland Food Consumption Survey: survey design and methodology. Public Health Nutr. 2001; 4(5A): 1037-42.

23 Robson PJ. Photographic food atlas for the North/South Ireland rood Consumption Survey, 1997.

24 Ministry of Agriculture, Fisheries and Food (MAFF). Food Portion Sizes. London: The Stationery Office, 1997.

25 Holland B, Welch AA, Unwin ID, Buss DH, Paul AA, Southgate DAT. McCance \& Widdowson's The Composition of Foods, 5th ed. Royal Society of Chemistry and Ministry of Agriculture, Fisheries and Food. London: HMSO, 1995.

26 Holland B, Unwin ID, Buss DH. Cereal and Cereal Products. Third Supplement to McCance \& Widdowson's The Composition of Foods, 4th ed. Royal Society of Chemistry and Ministry of Agriculture, Fisheries and Food. London: HMSO, 1988.

27 Holland B, Unwin ID, Buss DH. Milk Products and Eggs. Fourth Supplement to McCance \& Widdowson's The Composition of Foods, 4th ed. Royal Society of Chemistry 
and Ministry of Agriculture, Fisheries and Food. London: HMSO, 1989.

28 Holland B, Unwin ID, Buss DH. Vegetables, Herbs and Spices. Fifth Supplement to McCance $\&$ Widdowson's The Composition of Foods, 4th ed. Royal Society of Chemistry and Ministry of Agriculture, Fisheries and Food. London: HMSO, 1991.

29 Holland B, Unwin ID, Buss DH. Fruit and Nuts. First Supplement to McCance \& Widdowson's The Composition of Foods, 5th ed. Royal Society of Chemistry and Ministry of Agriculture, Fisheries and Food. London: HMSO, 1992.

30 Holland B, Welch AA, Buss DH. Vegetable Dishes. Second Supplement to McCance \& Widdowson's The Composition of Foods, 5th ed. The Royal Society of Chemistry and Ministry of Agriculture, Fisheries and Food. London: HMSO, 1992.

31 Holland B, Brown J, Buss DH. Fish and Fish Products. Third Supplement to McCance \& Widdowson's The Composition of Foods, 5th ed. Royal Society of Chemistry and Ministry of Agriculture, Fisheries and Food. London: HMSO, 1993.

32 Chan W, Brown J, Buss DH. Miscellaneous Foods. Fourth Supplement to McCance \& Widdowson's The Composition of Foods, 5th ed. Royal Society of Chemistry and Ministry of Agriculture, Fisheries and Food. London: HMSO, 1994.

33 Chan W, Brown J, Lee SM, et al. Meat, Poultry and Game. Fifth Supplement to McCance \& Widdowson's The Composition of Foods, 5th ed. Royal Society of Chemistry and Ministry of Agriculture, Fisheries and Food. London: HMSO, 1995.

34 Chan W, Brown J, Church SM, et al. Meat Products and Dishes. Sixth Supplement to McCance \& Widdowson's The Composition of Foods, 5th ed. Royal Society of Chemistry and Ministry of Agriculture, Fisheries and Food. London: HMSO, 1996.

35 Wearne SJ, Day MJL. Clues for the development of foodbased dietary guidelines: how are dietary targets being achieved by UK consumers? Br. J. Nutr. 1999; 81(Suppl. 2): S119-26.

36 Ministry of Agriculture, Fisheries and Food (MAFF). The Dietary and Nutritional Survey of British Adults - Further Analysis. London: HMSO, 1994.

37 Irish Nutrition and Dietetic Institute. Unpublished data from the database of the Irish National Nutrition Survey (INNS) 1990. Dublin: Irish Nutrition and Dietetic Institute, 2000.

38 Coakes SJ, Steed LG. SPSS without Anguish Versions 7.0, 7.5, 8.0 for Windows. Brisbane: John Wiley and Sons, 1999.

39 Black AE, Goldberg GR, Jebb SA, Livingstone MBE, Cole TJ, Prentice AM. Critical evaluation of energy intake data using fundamental principles of energy physiology: 2. Evaluating the results of published surveys. Eur. J. Clin. Nutr. 1991; 45: 583-99.

40 Goldberg GR, Black AE, Jebb SA, Cole TJ, Murgatroyd PR, Coward WA, Prentice AM. Critical evaluation of energy intake data using fundamental principles of energy physiology: 1. Derivation of cut-off limits to identify under-recording. Eur. J. Clin. Nutr. 1991; 45: 569-81.

41 Livingstone MBE. Assessment of food intakes: are we measuring what people eat? Br. J. Biomed. Sci. 1995; 52: 58-67.

42 McGowan MJ, Harrington $\mathrm{KE}$, Kiely $M$, Robson PJ, Livingstone MBE, Gibney MJ. An evaluation of energy intakes and the ratio of energy intake to estimated basal metabolic rate $\left(\mathrm{EI} / \mathrm{BMR}_{\mathrm{est}}\right)$ in the North/South Ireland Food
Consumption Survey. Public Health Nutr. 2001; 4(5A): 1043-50.

43 Becker W. Dietary guidelines and patterns of food and nutrient intake in Sweden. 1999; Br. J. Nutr. 81(Suppl. 2): S113-7.

44 Hermann-Kunz E, Thamm M. Dietary recommendations and prevailing food and nutrient intakes in Germany. Br.J. Nutr. 1999; 81(Suppl. 2): S61-9.

45 McCarthy SN, Harrington KE, Kiely M, Flynn A, Robson PJ, Livingstone MBE, Gibney MJ. Analyses of the anthropometric data from the North/South Ireland Food Consumption Survey. Public Health Nutr. 2001; 4(5A): 1099-106.

46 Briefel RR, Sempos CT, McDowell MA, Chien S, Alaimo K Dietary methods research in the third National Health and Nutrition Examination Survey: underreporting of energy intake. Am. J. Clin. Nutr. 1997; 65(Suppl.): 1203S-9S.

47 Pryer JA, Vrijheid M, Nichols R, Kiggins M, Elliott P. Who are the low energy reporters in the Dietary and Nutritional Survey of British Adults? Int. J. Epidemiol. 1997; 26: 14653.

48 Price GM, Paul AA, Cole TJ, Wadsworth MEJ. Characteristics of the low-energy reporters in a longitudinal national dietary survey. Br. J. Nutr. 1997; 77: 833-51.

49 Margetts BM, Nelson M. Design Concepts in Nutritional Epidemiology, 2nd ed. Oxford: Oxford University Press, 1997.

50 Becker W, Foley S, Shelley E, Gibney M. Energy underreporting in Swedish and Irish dietary surveys: implications for food-based dietary guidelines. Br. J. Nutr. 1999; 81(Suppl. 2): S127-31.

51 Hirvonen T, Männistö S, Roos E, Pietinen P. Increasing prevalence of under-reporting does not necessarily distort dietary surveys. Eur. J. Clin. Nutr. 1997; 51: 297-301.

52 Haraldsdóttir J. Dietary guidelines and patterns of intake in Denmark. Br. J. Nutr. 1999; 81(Suppl. 2): S43-8.

53 De Henauw S, De Backer G. Nutrient and food intakes in selected subgroups of Belgian adults. Br. J. Nutr. 1999; 81(Suppl. 2): S37-42.

54 Department of Health. Sensible Drinking. The Report of an Inter-Governmental Working Group. London: Department of Health, 1995.

55 Department of Health and Children. A Health Promotion Strategy: Making the Healthier Choice the Easier Choice. Dublin: Department of Health and Children, 1995.

56 Thakker KD. An overview of health risks and benefits of alcohol consumption. Alcohol Clin. Exp. Res. 1998; 22(Suppl. 7): 285S-98S.

57 Ahlawat SK, Siwach SB. Alcohol and coronary artery disease. Int. J. Cardiol. 1994; 44: 157-62.

58 Steinberg D, Pearson TA, Kuller LH. Alcohol and atherosclerosis. Ann. Intern. Med. 1991; 1: 967-76.

59 Millward DJ. Optimal protein intakes in the human diet. Proc. Nutr. Soc. 1999; 58: 403-13.

60 Hannon EM, Kiely M, Harrington KE, Robson PJ, Strain JJ, Flynn A. The North/South Ireland Food Consumption Survey: mineral intakes in 18-64-year-old adults. Public Health Nutr. 2001; 4(5A): 1081-88.

61 European Commission. Report on Osteoporosis in the European Community: Action for Prevention. EUR-OP ed. Luxembourg: European Commission, 1998.

62 National Osteoporosis Society. Facts and Figures on Osteoporosis. Bath, UK: National Osteoporosis Society, 2000. 